\title{
Galectin-3 inhibition ameliorates hypoxia-induced pulmonary artery hypertension
}

\author{
MINGWEN HAO ${ }^{1}$, MIAOMIAO $\mathrm{LI}^{2}$ and WENJUN LI ${ }^{1}$ \\ Departments of ${ }^{1}$ Thoracic Surgery and ${ }^{2}$ General Surgery, \\ The Affiliated Yantai Yuhuangding Hospital of Qingdao University, Yantai, Shandong 264000, P.R. China
}

Received October 16, 2015; Accepted September 19, 2016

DOI: $10.3892 / \mathrm{mmr} .2016 .6020$

\begin{abstract}
Galectin-3 (Gal-3) is a $\beta$-galactoside-binding lectin, which is important in inflammation, fibrosis and heart failure. The present study aimed to investigate the role and mechanism of Gal-3 in hypoxia-induced pulmonary arterial hypertension (PAH). Male C57BL/6J and Gal-3/- mice were exposed to hypoxia, then the right ventricular systolic pressure (RVSP) and Fulton's index were measured, and Gal-3 mRNA and protein expression in the pulmonary arteries was analyzed by reverse transcription-quantitative polymerase chain reaction and western blotting. Compared with the control, hypoxia increased the mRNA and protein expression levels of Gal-3 in wild type murine pulmonary arteries. Gal-3 deletion reduced the hypoxia-induced upregulation of RVSP and Fulton's index. Furthermore, human pulmonary arterial endothelial cells (HPAECs) and human pulmonary arterial smooth muscle cells (HPASMCs) were stimulated by hypoxia in vitro, and Gal-3 expression was inhibited by small interfering RNA. The inflammatory response of HPAECs, and the proliferation and cell cycle distribution of HPASMCs was also analyzed. Gal-3 inhibition alleviated the hypoxia-induced inflammatory response in HPAECs, including tumor necrosis factor- $\alpha$ and interleukin-1 secretion, expression of intercellular adhesion molecule-1 and adhesion of THP-1 monocytes. Gal-3 inhibition also reduced hypoxia-induced proliferation of HPASMCs, partially by reducing cyclin D1 expression and increasing p27 expression. Furthermore, Gal-3 inhibition suppressed HPASMC switching from a 'contractile' to a 'synthetic' phenotype. In conclusion, Gal-3 serves a fundamental role in hypoxia-induced PAH, and inhibition of Gal-3 may represent a novel therapeutic target for the treatment of hypoxia-induced $\mathrm{PAH}$.
\end{abstract}

Correspondence to: Dr Wenjun Li, Department of Thoracic Surgery, The Affiliated Yantai Yuhuangding Hospital of Qingdao University, 20 Yuhuangding Dong Road, Yantai, Shandong 264000, P.R. China

E-mail: icuqwd@163.com

Key words: pulmonary arterial hypertension, Galectin-3, inflammatory response, proliferation, phenotype

\section{Introduction}

Pulmonary arterial hypertension (PAH) is a progressive and life-threatening disease that results in a progressive increase in pulmonary vascular resistance, cardiac failure and mortality (1). Chronic hypoxia is an important contributing factor to $\mathrm{PAH}$, which is characterized by pulmonary vascular remodeling (2). The remodeling process includes proliferation of intima, hypertrophy of the medial and adventitial layers, and deposition of extracellular matrix $(3,4)$. Pulmonary arteries display complex structural and functional changes in $\mathrm{PAH}$, and endothelial cell dysfunction is important in disease progression; various cell types, growth factors and their receptors have been implicated in the development of PAH $(5,6)$. Vascular smooth muscle cells (VSMCs) are present in the medial wall of blood vessels and are normally quiescent, expressing a differentiated phenotype to maintain vascular tone under normal physiological conditions. However, under pathological conditions, VSMCs can switch to a 'synthetic' phenotype in which they secrete inflammatory cytokines and contribute to the vascular pathogenesis (7). Unfortunately, few therapies have, so far, proven to be effective against pulmonary arterial structure remodeling following the development of PAH.

Galectin-3 (Gal-3) is an important member of the lectin family, and is composed of a highly conserved N-terminal domain and a C-terminal carbohydrate recognition domain that preferentially interacts with $\beta$-galactosides (8). It is expressed in various cell types, including fibroblasts, endothelial cells and inflammatory cells (9-11), within the cytoplasm, nucleus, and extracellular space, and binds to the cell surface (12). Gal-3 is involved in numerous physiological and pathological processes, and has been demonstrated to be a central contributor to the progression of atherosclerotic plaques by amplification of key proinflammatory molecules in the aorta (13). Furthermore, Gal-3 is closely associated with cardiac dysfunction via induction of cardiac fibroblast proliferation, collagen deposition and ventricular dysfunction (14). However, to the best of our knowledge, its effects on PAH have not thus far been investigated. Considering the pathophysiology of PAH and the physiological role of Gal-3, it is reasonable to hypothesize that Gal-3 is associated with the pathogenesis of $\mathrm{PAH}$, an angioproliferative vasculopathy.

In the present study, Gal-3 was hypothesized to be involved in hypoxia-induced PAH. The role and underlying mechanism 
of Gal-3 in hypoxia-induced PAH was investigated in vitro and in vivo.

\section{Materials and methods}

Animals. The study was approved by the ethics committee of the Medical College of Qingdao University (approval no. 2015-107; Qingdao, China). A total of 45 mice were obtained from Jackson Laboratory (Bar Harbor, ME, USA): 30 male C57BL/6J mice, aged 10 weeks, 20-25 g; and 15 male Gal-3 $3^{-/}$mice, aged 10 weeks, 20-25 g (15). The C57BL/6J mice were randomly divided into two groups: The normal control group (15 mice) and the hypoxia group (15 mice). The C57BL/6J mice in the control group were exposed to normoxic conditions, whereas the C57BL/6J mice in the hypoxia group and the $15 \mathrm{Gal}-3^{-/ 2}$ mice were exposed to hypoxic conditions $\left(10 \% \mathrm{O}_{2}\right)$ using a 500-liter ventilated chamber (Flufrance Apparatus, Cachan, France) for 4 weeks as described previously (16). All animals were kept in the same room on a $12 \mathrm{~h}$ light: $12 \mathrm{~h}$ dark cycle at $22^{\circ} \mathrm{C}$, and had ad libitum access to standard mouse chow and water. The investigation was performed in accordance with the Guide for the Care and Use of Laboratory Animals (publication no. 82-23, revised in 1996; National Institutes of Health, Bethesda, MD, USA).

Measurement of right ventricular systolic pressure (RVSP) and Fulton's index. Prior to euthanasia by intraperitoneal administration of ketamine $(100 \mathrm{mg} / \mathrm{kg})$ and xylazine $(10 \mathrm{mg} / \mathrm{kg})$, the RVSP of mice was measured by right heart catheterization. Briefly, mice were anesthetized with intraperitoneal injection of pentobarbital sodium $(50 \mathrm{mg} / \mathrm{kg})$, then orally intubated and ventilated using a rodent respirator (Harvard Apparatus, Holliston, MA, USA). The tidal volume was set at $250 \mu \mathrm{l}$, and the respiratory rate was set at 120 breaths per minute. The right jugular vein was isolated, and a small polyethylene catheter was passed through a small transverse cut and advanced into the right ventricle. RVSP was recorded using a miniature pressure transducer (MPCU-200; Millar, Inc., Houston, TX, USA) digitized by a data acquisition system (ML800 Powerlab 16/30, ADInstruments, Ltd., Oxford, UK). Following measurement of RVSP, the right ventricle (RV), left ventricle (LV) and the septum (S) were isolated and weighed, and the Fulton's index was calculated according to the following formula: Fulton's index $=\mathrm{RV} /(\mathrm{LV}+\mathrm{S})$.

Cell culture and cell transfection. Human pulmonary arterial endothelial cells (HPAECs, catalog no. PCS-100-022) and human pulmonary arterial smooth muscle cells (HPASMCs, catalog no. PCS-100-023) were purchased from the American Type Culture Collection (ATCC; Manassas, VA, USA) and cultured in endothelial cell medium or smooth muscle cell medium (ScienCell Research Laboratories, San Diego, CA, USA) containing $10 \%$ fetal bovine serum (FBS; Gibco; Thermo Fisher Scientific, Inc., Waltham, MA, USA) at $37^{\circ} \mathrm{C}$ in a $5 \% \mathrm{CO}_{2}$ and $95 \%$ air atmosphere. Cells were used for the subsequent experiments up to passage 4. THP-1 monocytes (catalog no. TIB-202; ATCC) were cultured in RPMI-1640 medium (Gibco; Thermo Fisher Scientific, Inc.) containing $2 \mathrm{mM}$ L-glutamine, 10\% FBS and $100 \mathrm{U} / \mathrm{ml}$ penicillin and
$100 \mu \mathrm{g} / \mathrm{ml}$ streptomycin (Gibco; Thermo Fisher Scientific, Inc.).

To inhibit Gal-3 expression in HPAECs and HPASMCs, cells were transfected with $50 \mathrm{nM}$ small interfering RNA (siRNA) negative control (si-NC) or $50 \mathrm{nM}$ Gal-3 siRNA (Shanghai GenePharma, Shanghai, China) in Optimem medium (Invitrogen; Thermo Fisher Scientific, Inc.) using Lipofectamine 2000 (Invitrogen; Thermo Fisher Scientific, Inc.) for $24 \mathrm{~h}$ at $37^{\circ} \mathrm{C}$. The sequences for siRNA were as follows: Gal-3 siRNA, 5'-GCUCCAUGAUGCGUUAUCU-3', and si-NC, 5'-UUGAUGUGUUUAGUCGCUA-3'. HPAECs and HPASMCs $\left(2 \times 10^{6}\right.$ cells) were then exposed to normoxic conditions (control group) or hypoxic conditions $\left(10 \% \mathrm{O}_{2}, 5 \%\right.$ $\mathrm{CO}_{2}$ ) in a cell culture incubator at $37^{\circ} \mathrm{C}$ for $48 \mathrm{~h}(14)$.

Measurement of HPASMC proliferation and flow cytometric analysis. For cell counting, HPASMCs were seeded in a 6-well plate at a density of 5,000 cells/well, then exposed to normal or hypoxic conditions, with or without Gal-3 siRNA transfection. At the end of the experiment, cells were washed in PBS, harvested with trypsin, and counted using a hemocytometer. Cell cycle distribution was detected through flow cytometry using a cell cycle analysis kit (catalog no. C1052; Beyotime Institute of Biotechnology, Haimen, China). Briefly, HPASMCs were seeded in a 6-well plate (Corning Incorporated, Corning, $\mathrm{NY}, \mathrm{USA}$ ) at a density of 5,000 cells/well at $37^{\circ} \mathrm{C}$ for $24 \mathrm{~h}$ and preincubated with $25 \mu \mathrm{M}$ diindolylmethane for $1 \mathrm{~h}$, then trypsinized and fixed with $70 \%$ ethanol at $4{ }^{\circ} \mathrm{C}$, overnight. The fixed cells were collected by centrifugation at $800 \times \mathrm{g}$ for $15 \mathrm{~min}$, washed once in PBS and incubated with $1 \mathrm{ml}$ propidium iodide (PI) staining buffer (20 $\mu \mathrm{g} / \mathrm{ml}$ PI and $50 \mu \mathrm{g} / \mathrm{ml}$ RNase A), then analyzed with a fluorescence-activated cell sorter (FACS). The cell cycle distributions were analyzed using Multicycle AV software version 1.0 (Phoenix Flow Systems, San Diego, CA, USA).

Reverse transcription-quantitative polymerase chain reaction $(R T-q P C R)$. Total RNA was extracted from homogenized pulmonary arteries using TRIzol reagent (Invitrogen; Thermo Fisher Scientific, Inc.). Purified RNA $(1 \mu \mathrm{g})$ was treated with DNase and reverse transcribed using RevertAid first strand cDNA synthesis kit (Thermo Fisher Scientific, Inc.) according to the manufacturer's protocol. mRNA expression was analyzed by RT-qPCR with iQ SYBR Green Supermix (Bio-Rad Laboratories, Inc., Hercules, CA, USA). qPCR was performed using the following primers: Cyclin D1, forward 5'-CAGACCAGCCTAACAGATTTC-3', reverse 5'-TGACCC ACAGCAGAAGAAG-3'; p27, forward 5'-CTTGGAGAA GCACTGCCGAGAT-3', reverse 5'-CCCTGGACACTGCTC CGCTA-3'; Gal-3, forward 5'-GTTATCTGGGTCTGGAAA CC-3', reverse 5'-TCTGTTTGCATTGGGCTTCACC-3'; and $\beta$-actin, forward 5'-ATCATGTTTGAGACCTTCAACA-3' and reverse 5'-CATCTCTTGCTCGAAGTCCA-3'. Amplification, detection, and data analysis involved the use of the iCycler version 3.1 real-time PCR system (Bio-Rad Laboratories, Inc.). PCR amplification cycling conditions were: $95^{\circ} \mathrm{C}$ for $5 \mathrm{~min}$, 36 cycles at $95^{\circ} \mathrm{C}$ for $10 \mathrm{sec}$, annealing at $56^{\circ} \mathrm{C}$ for $30 \mathrm{sec}$ and elongation at $72^{\circ} \mathrm{C}$ for $30 \mathrm{sec}$. The relative expression of genes was obtained using the $2^{-\Delta \Delta \mathrm{Cq}}$ calculation method (17). Each sample was analyzed in triplicate, and the expression was normalized to that of $\beta$-actin. 
Western blot analysis. Total protein was extracted from homogenized murine pulmonary arteries and HPASMCs using radioimmunoprecipitation assay lysis buffer (Beyotime Institute of Biotechnology), then centrifuged at 10,000 $\mathrm{x} g$ for $5 \mathrm{~min}$ and the supernatant was collected. The protein concentrations were assayed by bicinchoninic assay (Beyotime Institute of Biotechnology). The samples (50 $\mu \mathrm{g}$ per lane) were separated on 10\% SDS-polyacrylamide gels and electrophoretically transferred onto nitrocellulose membranes (EMD Millipore, Billerica, MA, USA). Membranes were blocked with $5 \%$ non-fat milk for $2 \mathrm{~h}$ at room temperature, then washed three times in TBS-0.1\% Tween 20 for $10 \mathrm{~min}$, and incubated with the appropriate primary antibodies: Rabbit anti-Gal-3 (catalog no. 87985; 1:1,000; Cell Signaling Technology, Inc., Danvers, MA, USA), rabbit anti-intercellular adhesion molecule 1 (ICAM-1; catalog no. 4915; 1:1,000; Cell Signaling Technology, Inc.), rabbit anti-cyclin D1 (catalog no. 2978; 1:1,000; Cell Signaling Technology, Inc.), rabbit anti-p27 (catalog no. ab32034; 1:500; Abcam, Cambridge MA, USA), rabbit anti- $\alpha$-smooth muscle actin (SMA; catalog no. 14968; 1:1,000; Cell Signaling Technology, Inc.), rabbit anti-smooth muscle calponin (CNN; catalog no. ab46794; $1: 1,000$; Abcam) or rabbit anti- $\beta$-actin (catalog no. 4970; 1:1,000; Cell Signaling Technology, Inc.) at $4^{\circ} \mathrm{C}$ overnight. Membranes were then washed three times in TBS+0.1\% Tween 20, then incubated with a horseradish peroxidase-conjugated secondary antibodies (catalog nos. ZB-2301 and ZB-2305; 1:1,000, ZSGB-BIO, Beijing, China) for $2 \mathrm{~h}$ at $25^{\circ} \mathrm{C}$. Immune complexes were detected using enhanced chemiluminescence (EMD Millipore) and analyzed by Image-Pro Plus 6.0 (Media Cybernetics, Inc., Rockville, MD, USA).

ELISA. Cell culture supernatants were obtained by centrifugation at $1,000 \times \mathrm{g}$ for $10 \mathrm{~min}$ at $4^{\circ} \mathrm{C}$. Secretion of tumor necrosis factor- $\alpha($ TNF- $\alpha$ ) and interleukin-1 $\beta$ (IL-1 $\beta)$ ) was determined using ELISA kits according to the manufacturer's protocols (catalog no. \#070133, Uscn Life Sciences, Inc., Wuhan, China and catalog no. FHK0016, Jiamay Biotech Co. Ltd., Beijing, China, respectively). All operations were performed at room temperature. Mean absorbance for standards and samples was assessed in duplicate. The color reaction was detected using a Varioskan Flash multifunction plate reader (Thermo Fisher Scientific, Inc.).

Monocyte adhesion assay. THP-1 monocyte adhesion assays were performed as previously described (18). Briefly, THP-1 cells $\left(5 \times 10^{5}\right.$ cells $\left./ \mathrm{ml}\right)$ were labeled with $10 \mu \mathrm{M}$ 2',7'-bis-(2-carboxyethyl)-5-(and-6)carboxyfluorescein, acetoxymethyl ester fluorescent dye (Beyotime Institute of Biotechnology) in serum-free RPMI-1640 medium (Gibco; Thermo Fisher Scientific, Inc.) for $45 \mathrm{~min}$ at $37^{\circ} \mathrm{C}$ with frequent agitation. Following exposure to hypoxia in the presence or absence of siRNA, the HPAEC monolayers (90\% confluence) were washed with endothelial cell medium and the THP- 1 cells $\left(5 \times 10^{5}\right.$ cells $)$ were added. Following incubation for $45 \mathrm{~min}$ at $37^{\circ} \mathrm{C}$, unbound monocytes were removed by washing with PBS, cells were then fixed with $4 \%$ paraformaldehyde and mounted onto a glass coverslip. Bound monocytes were quantified by counting the cells under a fluorescent microscope (two wells for each condition, with five fields of view assessed).

Statistical analysis. Data are expressed as the mean \pm standard deviation of at least three replicates. Analyses were performed using SPSS version 13.0 for Windows (SPSS, Inc., Chicago, IL, USA). All statistical comparisons were performed using one-way analysis of variance with least significant difference post-hoc analysis or Chi-squared tests. $\mathrm{P}<0.05$ was considered to indicate a statistically significant difference.

\section{Results}

Gal-3 inhibition reduces the hypoxia-induced increase in RVSP and Fulton's index in vivo. Gal-3 mRNA and protein expression levels were examined in three groups of mice: i) Wild type mice in normoxic conditions; ii) wild type mice in hypoxic conditions; and iii) Gal- $3^{-/}$mice in hypoxic conditions. Gal-3 mRNA and protein expression was undetectable in Gal-3 $3^{-/}$mice (Fig. 1A and B), whereas Gal-3 mRNA and protein expression in hypoxic wild type mice were significantly increased compared with the normoxic control group $(\mathrm{P}<0.001$ and $\mathrm{P}<0.001$, respectively; Fig. $1 \mathrm{~A}$ and $\mathrm{B})$. The hypothesis that Gal-3 deletion may alleviate PAH in mice was then examined through measurement of hemodynamic parameters prior to euthanasia. No significant difference was observed in mean blood pressure and heart rate between the groups (data not shown). Compared with normoxic wild type control mice, mice in the wild type hypoxia group had a higher RVSP $(\mathrm{P}<0.001$; Fig. 1C). However, the RVSP was significantly reduced in hypoxic Gal- $3^{-/}$mice compared with hypoxic wild type mice $(\mathrm{P}=0.002$; Fig. 1C). It has previously been demonstrated that exposure to chronic hypoxia promotes right ventricular hypertrophy (19); in the present study, Fulton's index was used to assess right ventricular hypertrophy. Hypoxia was demonstrated to significantly increase the Fulton's index in wild type mice compared with normoxic wild type control mice $(\mathrm{P}<0.001$; Fig. 1D), whereas it was reduced in hypoxic Gal- $3^{-/}$mice compared with hypoxic wild type mice $(\mathrm{P}<0.001$; Fig. 1D). These findings suggest that deletion of Gal-3 reduces hypoxia-induced increases in RVSP and RV hypertrophy.

Hypoxia induces in vitro expression of Gal-3. The effect of hypoxia on Gal-3 expression was then investigated in vitro. Gal-3 mRNA and protein expression levels were detected in HPAECs and HPASMCs cultured under normoxic and hypoxic conditions. HPAECs and HPASMCs were also transfected with si-Gal-3 siRNA to inhibit Gal-3 expression and si-NC, and cultured under hypoxic conditions. Compared with the normoxic control group, hypoxia significantly increased Gal-3 mRNA and protein expression levels in untransfected cells $(\mathrm{P}<0.05$; Fig. 2$)$, whereas hypoxic cells transfected with si-Gal-3 demonstrated significantly reduced levels of Gal-3 mRNA and protein expression compared with untransfected hypoxic cells ( $\mathrm{P}<0.05$; Fig. 2).

Gal-3 inhibition reduces the hypoxia-induced inflammatory response. Following $48 \mathrm{~h}$ stimulation of HPAECs with hypoxia, TNF- $\alpha$ and IL-1 secretion levels were assessed by ELISA (Fig. 3A and B), ICAM-1 protein expression levels 

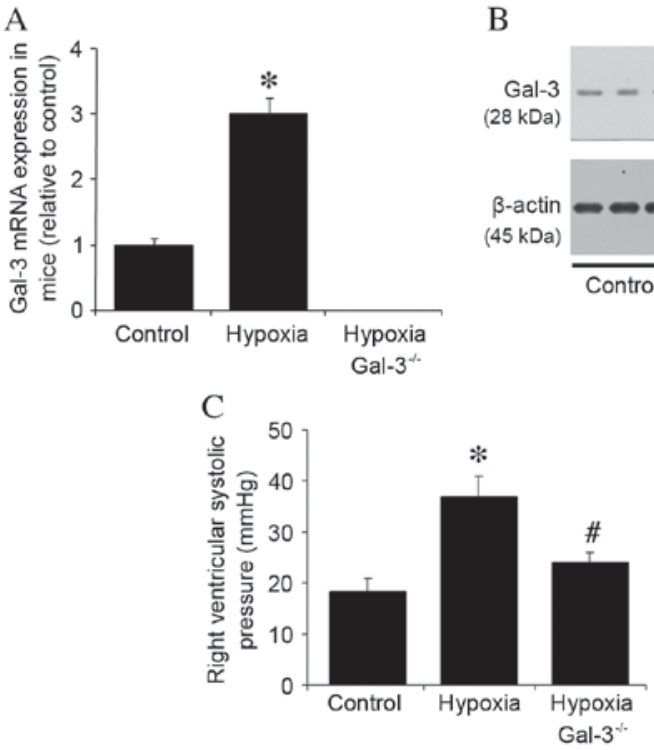
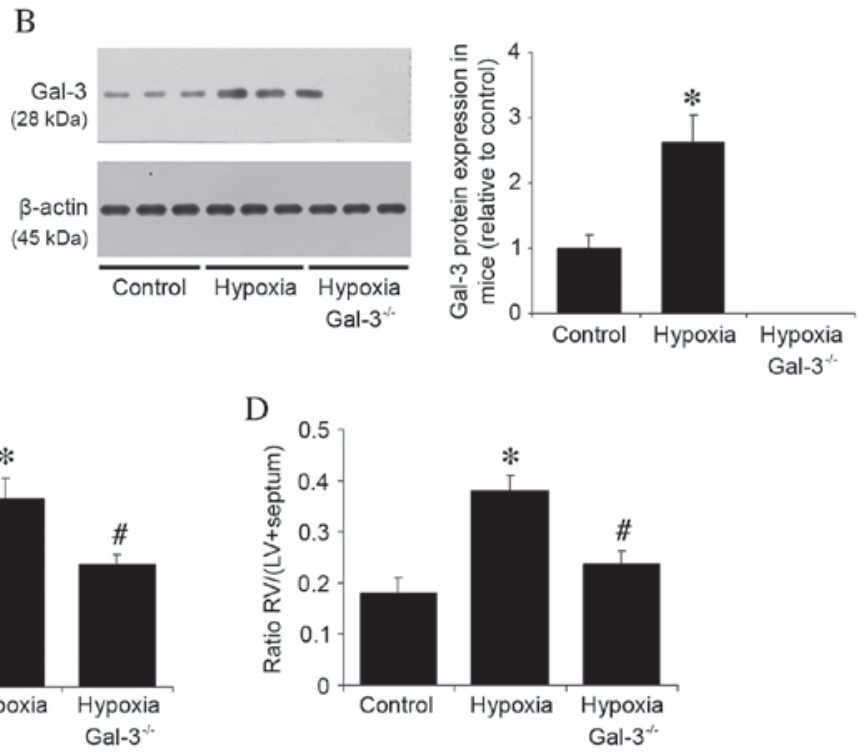

Figure 1. Hypoxia increases Gal-3 mRNA and protein expression, RVSP and Fulton's index in wild type mice, whereas Gal-3 deletion reduces the increase of RVSP and Fulton's index induced by hypoxia. (A) Gal-3 mRNA expression was assessed by reverse transcription-quantitative polymerase chain reaction, with quantitation relative to $\beta$-actin $(n=3)$. (B) Gal-3 protein expression was assessed by western blot analysis, with quantitation relative to $\beta$-actin ( $\mathrm{n}=3$ ). (C) Measurement of RVSP. (D) Measurement of Fulton's index. Data are presented as the mean \pm standard deviation. ${ }^{*} \mathrm{P}<0.05$ vs. normoxic control; ${ }^{\sharp} \mathrm{P}<0.05$ vs. hypoxia. Gal-3, galectin-3; RVSP, right ventricular systolic pressure; RV, right ventricle; LV, left ventricle.

A
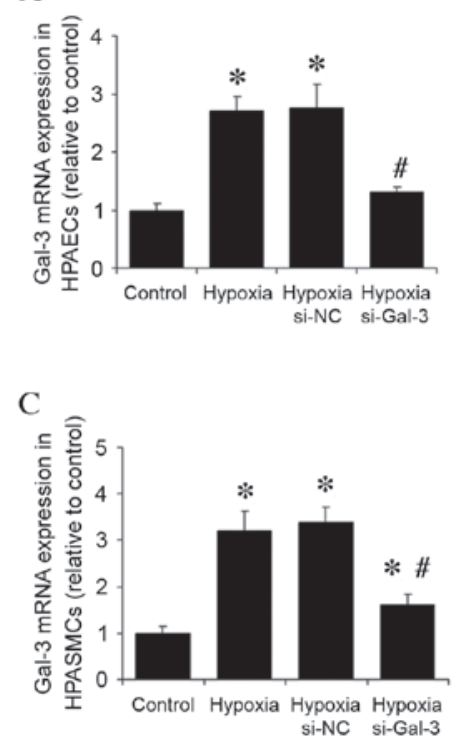

B

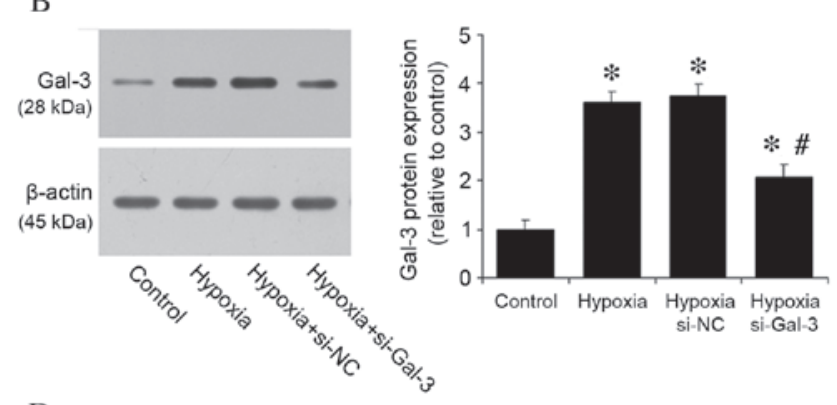

$\mathrm{D}$

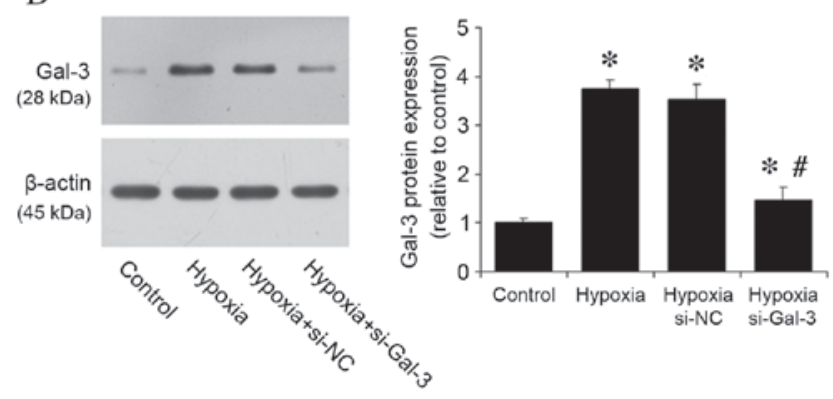

Figure 2. Hypoxia increases Gal-3 mRNA and protein expression in HPAECs and HPASMCs. (A) Gal-3 mRNA expression in HPAECs was assessed by RT-qPCR, with quantitation relative to $\beta$-actin. (B) Gal-3 protein expression in HPAECs was assessed by western blot analysis, with quantitation relative to $\beta$-actin. Hypoxia increased mRNA and protein expression levels of Gal-3 in HPAECs, whereas Gal-3 inhibition by siRNA reduced expression. (C) Gal-3 mRNA expression in HPASMCs was assessed by RT-qPCR, with quantitation relative to $\beta$-actin. (D) Gal-3 protein expression in HPASMCs was assessed by western blot analysis, with quantitation relative to $\beta$-actin. Hypoxia increased Gal-3 mRNA and protein expression levels in HPASMCs, whereas Gal-3 inhibition reduced expression. Data are presented as the mean \pm standard deviation of three independent replicates. ${ }^{*} \mathrm{P}<0.05$ vs. normoxic control; ${ }^{*} \mathrm{P}<0.05$ vs. hypoxia. Gal-3, galectin-3; HPAECs, human pulmonary arterial endothelial cells; HPASMCs, human pulmonary arterial smooth muscle cells; si-NC, negative control small interfering RNA; si-Gal-3, Gal-3 small interfering RNA; RT-qPCR, reverse transcription-quantitative polymerase chain reaction.

were analyzed by western blotting (Fig. 3C), and THP-1 monocyte adhesion was analyzed by monocyte adhesion assay (Fig. 3D). Compared with the normoxic control group, hypoxia increased TNF- $\alpha$ and IL- 1 secretion $(\mathrm{P}<0.001$ and $\mathrm{P}<0.001$, respectively; Fig. 3A and $\mathrm{B}$, respectively), ICAM-1 protein expression $(\mathrm{P}<0.001$; Fig. 3C), and the number of adhered THP-1 cells $(\mathrm{P}<0.001$; Fig. 3D). Gal-3 inhibition in hypoxic cells resulted in reduced TNF- $\alpha$ and IL-1 secretion $(\mathrm{P}<0.001$ and $\mathrm{P}<0.001$, respectively; Fig. $3 \mathrm{~A}$ and $\mathrm{B}$ ), reduced ICAM-1 protein expression $(\mathrm{P}<0.001$; Fig. 3C), and fewer adhered 
A

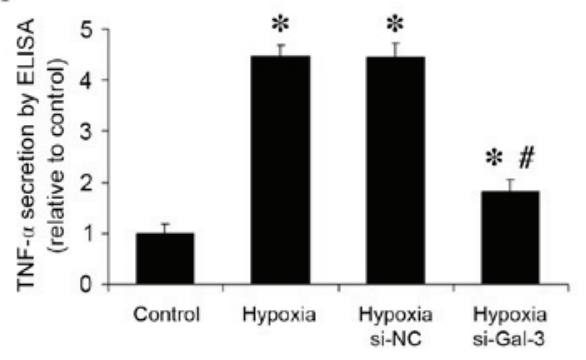

C

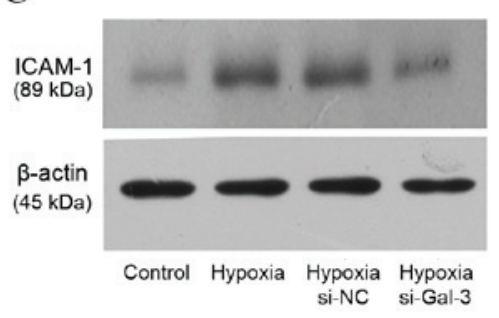

D

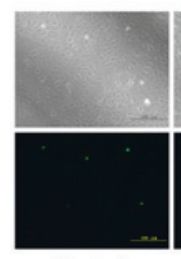

Control

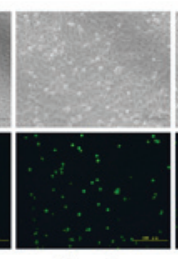

Hypoxia

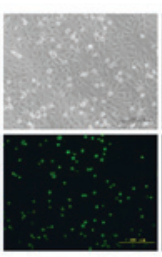

Hypoxia

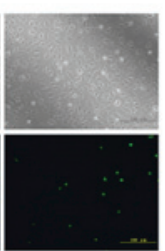

Hypoxia
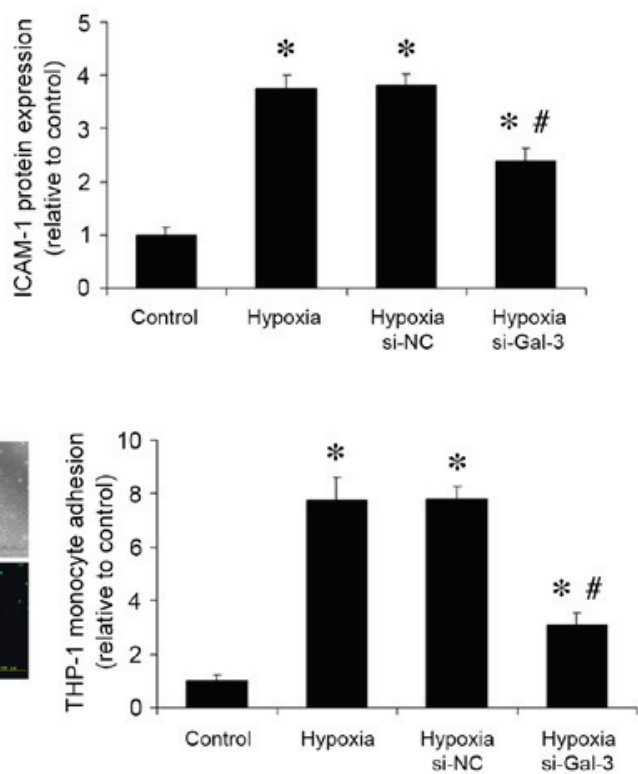

Figure 3. Gal-3 inhibition reduces the hypoxia-induced inflammatory response in HPAECs. (A) TNF- $\alpha$ and (B) IL-1 secretion were assessed by ELISA. (C) ICAM-1 protein expression levels were detected by western blot analysis, with quantitation relative to $\beta$-actin. (D) Representative images of THP-1 monocyte adhesion assays, with quantitation of three independent replicates. Scale bar $=100 \mu \mathrm{m}$. Data are presented as the mean \pm standard deviation of three independent replicates. "P $<0.05$ vs. normoxic control; ${ }^{*} \mathrm{P}<0.05$ vs. hypoxia. Gal-3, galectin-3; HPAECs, human pulmonary arterial endothelial cells; si-NC, negative control small interfering RNA; si-Gal-3, Gal-3 small interfering RNA; TNF- $\alpha$, tumor necrosis factor $\alpha$; IL-1, interleukin 1; ICAM-1, intercellular adhesion molecule 1 .

THP-1 cells $(\mathrm{P}<0.05$; Fig. 3D) compared with untransfected hypoxic cells.

Gal-3 inhibition reduces hypoxia-induced HPASMC proliferation. Following $48 \mathrm{~h}$ of hypoxic stimulation of HPASMCs, cells were harvested and counted using a hemocytometer (Fig. 4A). The mean number of viable HPASMCs in the hypoxia group was 1.65 -fold higher than that in the normoxic control group ( $\mathrm{P}=0.002$; Fig. 4B). However, Gal-3 inhibition in hypoxic cells significantly reduced the mean number of viable HPASMCs compared with untransfected hypoxic cells $(\mathrm{P}=0.019$; Fig. 4B).

Gal-3 inhibition results in HPASMC arrest in $G_{0} / G_{1}$-phase under conditions of hypoxia. Cell proliferation depends on cell cycle transition from $\mathrm{G}_{0} / \mathrm{G}_{1}$-phase to $\mathrm{S}$-phase and $\mathrm{G}_{2} / \mathrm{M}$-phase. The effect of Gal-3 inhibition on the cell cycle distribution of HPASMCs was, therefore, analyzed. Hypoxia reduced the number of cells in $\mathrm{G}_{0} / \mathrm{G}_{1}$-phase compared with normoxic control cells ( $\mathrm{P}=0.032$; Fig. 4C), whereas Gal-3 inhibition in hypoxic cells arrested more HPASMCs in the $G_{0} / G_{1}$-phase $(\mathrm{P}=0.046$; Fig. 4C).
Gal-3 inhibition reduces cyclin D1 expression, but increases p27 expression. The underlying mechanism of Gal-3 modulation on cell proliferation and the cell cycle was then investigated. Previous studies have demonstrated that cyclin D1 and p27 are important in cell proliferation and the cell cycle (20); therefore, their mRNA and protein expression levels were examined in vitro. RT-qPCR revealed that mRNA expression levels of cyclin D1 were significantly reduced by Gal-3 inhibition in hypoxic cells compared with untransfected hypoxic cells ( $\mathrm{P}=0.002$; Fig. 5A), whereas Gal-3 inhibition in hypoxic cells increased p27 mRNA expression compared with untransfected hypoxic cells ( $\mathrm{P}=0.048$; Fig. 5B). Western blot analysis of protein expression levels revealed the same pattern of reduced cyclin D1 protein expression and increased p27 protein expression in hypoxic Gal-3 inhibited cells compared with untransfected hypoxic cells $(\mathrm{P}<0.001$ and $\mathrm{P}=0.003$, respectively; Fig. 5C and D). These results suggest that Gal-3 inhibition may alleviate PAH via regulation of cell cycle.

Gal-3 inhibition suppresses HPASMC transition from 'contractile' to 'synthetic' phenotype. Under pathological conditions, VSMCs can switch to a 'synthetic' phenotype with 


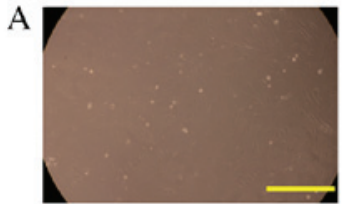

Control

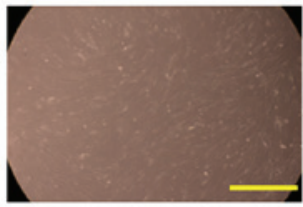

Hypoxia

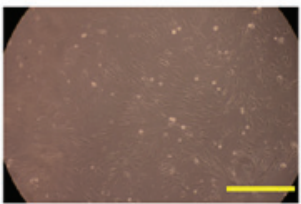

Hypoxia

si-NC

C

B

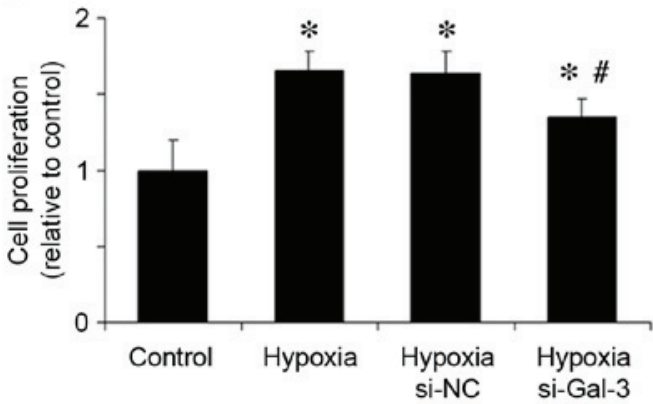

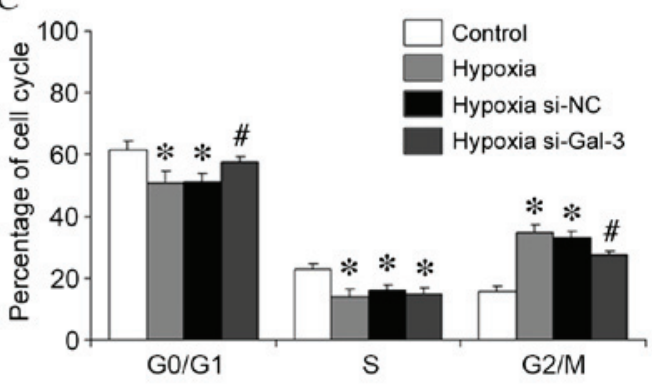

Figure 4. Gal-3 inhibition reduces hypoxia-induced proliferation of HPASMCs by arrest in $\mathrm{G}_{0} / \mathrm{G}_{1}$-phase. (A) Light microscope images of HPASMC morphology. Scale bar: $100 \mu \mathrm{m}$. (B) HPASMC proliferation was assessed using a hemocytometer. (C) Cell cycle distribution was detected by flow cytometry. Data are presented as the mean \pm standard deviation of three independent replicates. " $\mathrm{P}<0.05$ vs. normoxic control; " $\mathrm{P}<0.05$ vs. hypoxia. Gal-3, galectin- 3 ; HPASMCs, human pulmonary arterial smooth muscle cells; si-NC, negative control small interfering RNA; si-Gal-3: Gal-3 small interfering RNA.

A

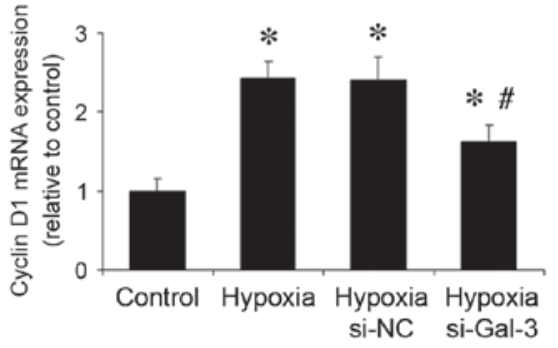

B
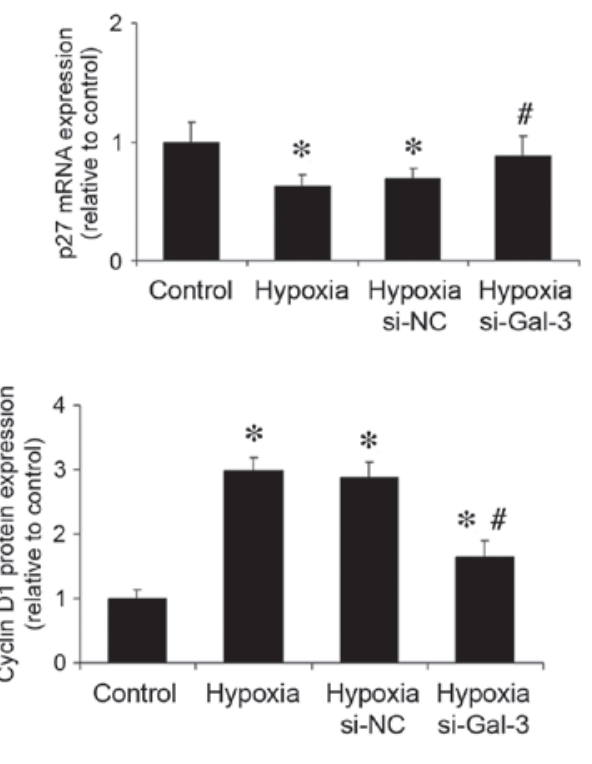

D

C
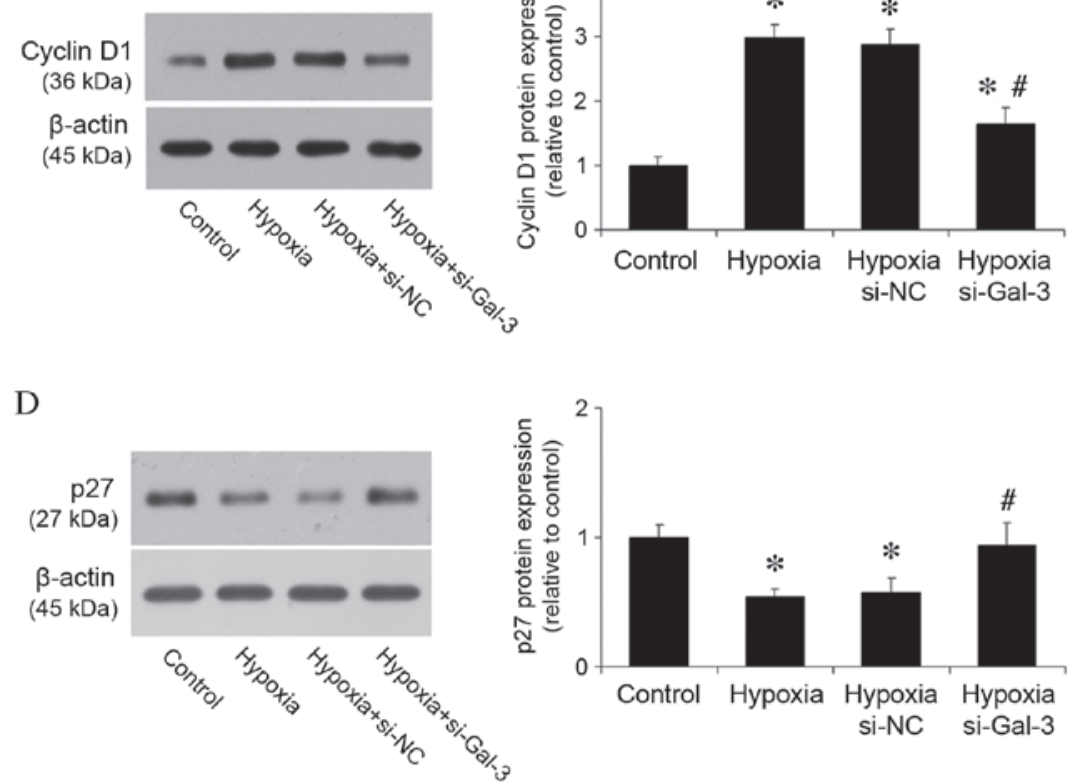

Figure 5. Gal-3 inhibition reduces cyclin D1 mRNA and protein expression, but increases p27 mRNA and protein expression in hypoxic HPASMCs. (A) Cyclin D1 and (B) p27 mRNA expression in HPASMCs was assessed by reverse transcription-quantitative polymerase chain reaction, with quantitation relative to $\beta$-actin. (C) Cyclin D1 and (D) p27 protein expression in HPASMCs was assessed by western blot analysis, with quantitation relative to $\beta$-actin. Data are presented as the mean \pm standard deviation of three independent replicates. ${ }^{*} \mathrm{P}<0.05$ vs. normoxic control; ${ }^{~} \mathrm{P}<0.05$ vs. hypoxia. Gal-3, galectin-3; HPASMCs, human pulmonary arterial smooth muscle cells; si-NC, negative control small interfering RNA; si-Gal-3, Gal-3 small interfering RNA; RT-qPCR. 

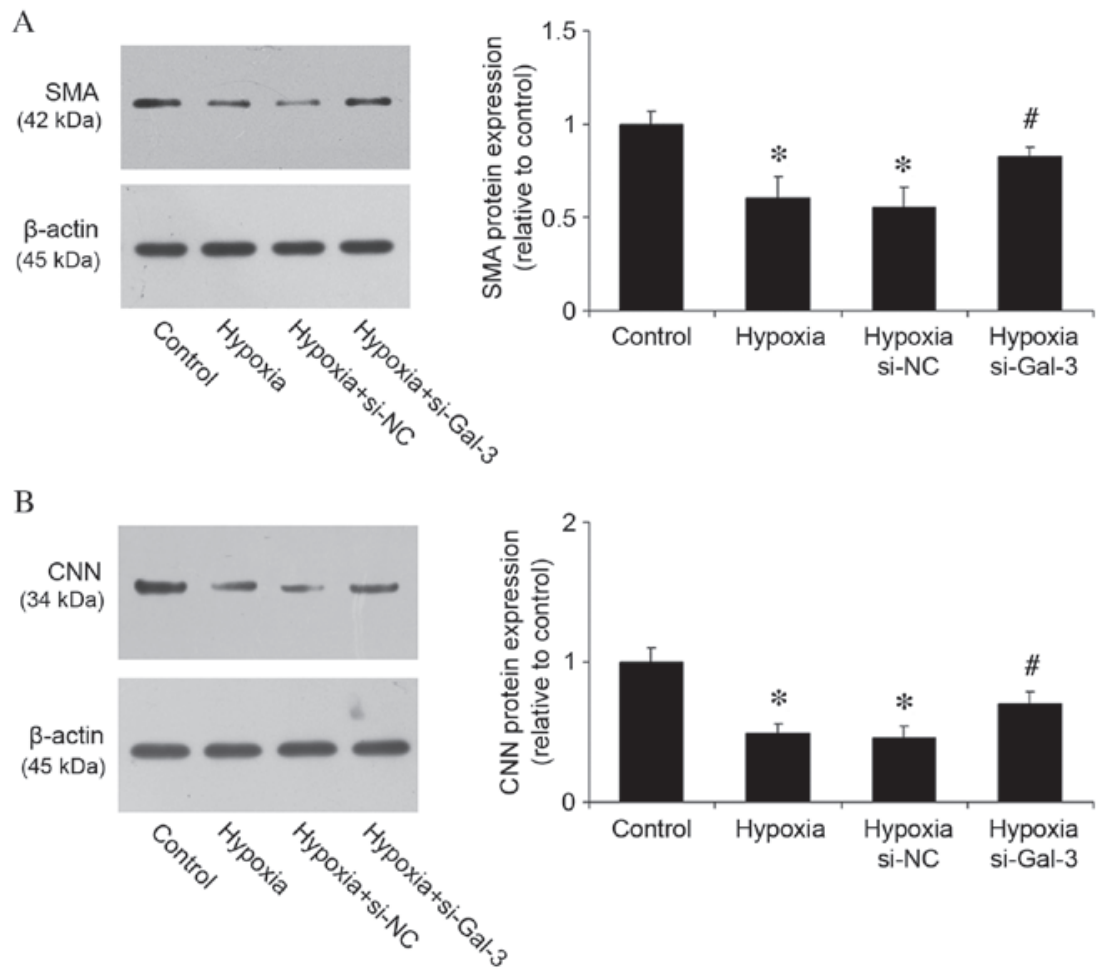

Figure 6. Gal-3 inhibition increases SMA and CNN protein expression in hypoxic HPASMCs. (A) SMA and (B) CNN protein expression in HPASMCs was assessed by western blotting analysis, with quantitation relative to $\beta$-actin. Hypoxia reduced the protein expression of SMA and CNN, whereas Gal-3 inhibition increased it. Data are presented as the mean \pm standard deviation of three independent replicates. ${ }^{*} \mathrm{P}<0.05$ vs. normoxic control; ${ }^{*} \mathrm{P}<0.05$ vs. hypoxia. Gal-3, galectin-3; HPASMCs, human pulmonary arterial smooth muscle cells; SMA, $\alpha$-smooth muscle actin; CNN, smooth muscle calponin; si-NC, negative control small interfering RNA; si-Gal-3, Gal-3 small interfering RNA.

a reduced expression of SMA and $\mathrm{CNN}$, in which they secrete inflammatory cytokines, and which contributes to vascular pathogenesis (21). To examine the effects of Gal-3 on phenotype switching, protein expression levels of SMA and CNN were measured in HPASMCs. Compared with the control group, hypoxia reduced the expression of SMA and CNN $(\mathrm{P}<0.001$ and $\mathrm{P}<0.001$, respectively; Fig. $6 \mathrm{~A}$ and $\mathrm{B})$, whereas Gal-3 inhibition increased their expression $(\mathrm{P}=0.017$ and $\mathrm{P}=0.021$, respectively; Fig. $6 \mathrm{~A}$ and $\mathrm{B}$ ). These results suggest a critical function of Gal-3 during the phenotype transition of HPASMCs.

\section{Discussion}

$\mathrm{PAH}$, which is characterized by a persistent increase in pulmonary artery pressure and pulmonary vascular remodeling, is a progressive disease that is associated with a poor prognosis (22). PAH is diagnosed when the mean pulmonary arterial pressure exceeds $25 \mathrm{mmHg}$, as measured by right-heart catheterization (18). Although advances have been made in the understanding of PAH and development of treatments, research into effective therapies is still required to improve the long-term survival of patients with fewer side effects than current treatments exert. It has been demonstrated that Gal-3 expression is increased in the left ventricle in the early ischemic period, which may be part of the prosurvival gene expression profile transcribed by hypoxia-inducible factor 1a (23). Increased expression of Gal-3 protects against cell death under conditions of hypoxia and nutrient deprivation (24). In the present study, Gal-3 was demonstrated to be associated with hypoxia-induced PAH. Exposure to chronic hypoxia resulted in significantly elevated RVSP and increased Fulton's index in wild type mice. However, the increase was inhibited in Gal-3 $3^{-/}$mice. Furthermore, Gal-3 inhibition reduced the hypoxia-induced inflammatory response in HPAECs and reduced HPASMC cell proliferation by arresting cells in $\mathrm{G}_{0} / \mathrm{G}_{1}$-phase. Gal-3 inhibition also resulted in reduced expression of cyclin D1 and increased p27 expression in HPASMCs, and inhibited the switch of HPASMCs to a 'synthetic' phenotype. These novel findings contribute to the understanding of the mechanism by which Gal-3 inhibition ameliorates hypoxia-induced PAH.

Inflammation is important during PAH disease progression (25). There is an increase in serum levels of several chemokines and cytokines related to inflammatory processes during PAH (26). Cytokines are a large group of signaling proteins, which regulate numerous biological processes, including inflammation, immunity and hematopoiesis. Cytokines, such as TNF- $\alpha$, IL- 8 and monocyte chemotactic protein-1, contribute to leukocyte recruitment, endothelin-1 induction, and smooth muscle cell (SMC) proliferation $(26,27)$. In a previous study, rats treated with a TNF- $\alpha$ inhibitor demonstrated amelioration in pulmonary hemodynamics, right ventricular hypertrophy and pulmonary inflammation (28). In the present study, hypoxia was demonstrated to increase TNF- $\alpha$ and IL-1 secretion, increase ICAM-1 protein expression and increase adhesion of THP-1 monocytes in vitro, whereas Gal-3 inhibition by siRNA was demonstrated to reduce the 
inflammatory response. This may be one mechanism by which Gal-3 inhibition protects against PAH.

Similar to other vasculopathies, PAH is characterized by severe angioproliferative vascular remodeling (29). The proliferation of HPASMCs is important in the progression of PAH; effective inhibition of aberrant HPASMC proliferation can delay, and even halt, the deteriorative progress of PAH (5). In the present study, under conditions of hypoxia, few HPASMCs remained in $\mathrm{G}_{0} / \mathrm{G}_{1}$ phase and more cells entered the mitotic cycle, whereas Gal-3 inhibition reduced hypoxia-induced HPASMC proliferation, partially through cell cycle arrest in $\mathrm{G}_{0} / \mathrm{G}_{1}$-phase. The possible mechanism underlying this effect was then investigated. The cell cycle is regulated by cyclin-dependent kinases (CDK) and CDK inhibitors, which have been key therapeutic targets in treating vascular proliferation-associated diseases (16). Cyclin D1 is the key cell cycle control gene that facilitates the transition of cells from the $\mathrm{G}_{1}$ phase into the $\mathrm{S}$ phase (18). A previous study demonstrated that inhibition of cyclin D1 could inhibit VSMC proliferation (30). The present study demonstrated that hypoxia increased the mRNA and protein expression of cyclin D1, whereas Gal-3 inhibition significantly reduced cyclin D1 expression. p27, which is an important CDK inhibitor, can effectively inhibit cyclin D1 activity and negatively regulate $\mathrm{G}_{1}$ progression in cells (31). It has been demonstrated that p27 is one of the potent inhibitors of VSMC growth in vivo and in vitro (32,33). Fouty et al (29) demonstrated that $\mathrm{p} 27$ modulates PASMC proliferation during mitogenic stimulation, and that overexpression of $\mathrm{p} 27$ decreases PASMC proliferation. The present study demonstrated that Gal-3 inhibition increases p27 mRNA and protein expression.

The principal phenotype of SMCs is contractile, which preserves vasodilation and blood flow regulation under normal physiological conditions. However, in pathological conditions, SMCs can transform from the differentiated contractile phenotype to a synthetic state, which is characterized by high proliferation, migration and extracellular matrix production. During this process, the contractile ability of SMCs is reduced, resulting in a lack of resistance to environmental stimulation (22). Normally, VSMCs express the contractile phenotype by regulating specific genes, including SMA, CNN and $\mathrm{SM} 22 \alpha$ (21). As a response to stimuli including inflammation, oxidative stress and shear stress, quiescent contractile cells reduce the expression of SMC-specific genes to promote their proliferation, migration and collagen synthesis, in order to remodel the phenotypic state into the synthetic state $(34,35)$. However, aberrant phenotype transitioning leads to pulmonary arterial remodeling. In the present study, hypoxia was observed to reduce SMA and CNN protein expression, whereas Gal-3 inhibition increased their expression. These results suggested that Gal-3 inhibition could suppress the transformation of HPASMCs from a contractile to a synthetic phenotype.

In conclusion, the present study presents evidence that Gal-3 inhibition reduces the increased RVSP and alleviated $\mathrm{RV}$ hypertrophy of mice with PAH. In vitro Gal-3 inhibition was also demonstrated to reduce the hypoxia-induced inflammatory response and reduce HPASMC proliferation by decreasing cyclin D1 expression and increasing p27 expression. Gal-3 inhibition also maintained a contractile phenotype in HPASMCs. These findings may lead to a useful therapeutic intervention for the treatment of pulmonary hypertensive disorders.

\section{Acknowledgements}

The present study was supported by a grant from the National Natural Science Foundation of China (grant no. 81400340).

\section{References}

1. Humbert M, Morrell NW, Archer SL, Stenmark KR, MacLean MR, Lang IM, Christman BW, Weir EK, Eickelberg O, Voelkel NF and Rabinovitch M: Cellular and molecular pathobiology of pulmonary arterial hypertension. J Am Coll Cardiol 43 (12 Suppl S): 13S-24S, 2004.

2. Sudar E, Dobutovic B, Soskic S, Mandusic V, Zakula Z, Misirkic M, Vucicevic L, Janjetovic K, Trajkovic V, Mikhailidis DP and Isenovic ER: Regulation of inducible nitric oxide synthase activity/expression in rat hearts from ghrelin-treated rats. J Physiol Biochem 67: 195-204, 2011.

3. Orlandi A, Bochaton-Piallat ML, Gabbiani G and Spagnoli LG: Aging, smooth muscle cells and vascular pathobiology: Implications for atherosclerosis. Atherosclerosis 188: 221-230, 2006.

4. Stenmark KR, Fagan KA and Frid MG: Hypoxia-induced pulmonary vascular remodeling: Cellular and molecular mechanisms. Circ Res 99: 675-691, 2006.

5. Luo Y, Xu DQ, Dong HY, Zhang B, Liu Y, Niu W, Dong MQ and Li ZC: Tanshinone IIA inhibits hypoxia-induced pulmonary artery smooth muscle cell proliferation via Akt/Skp2/p27-associated pathway. PLoS One 8: e56774, 2013.

6. Vasa M, Fichtlscherer S, Adler K, Aicher A, Martin H, Zeiher AM and Dimmeler S: Increase in circulating endothelial progenitor cells by statin therapy in patients with stable coronary artery disease. Circulation 103: 2885-2890, 2001.

7. Chen B, Calvert AE, Cui H and Nelin LD: Hypoxia promotes human pulmonary artery smooth muscle cell proliferation through induction of arginase. Am J Physiol Lung Cell Mol Physiol 297: L1151-L1159, 2009.

8. Dennis JW, Pawling J, Cheung P, Partridge E and Demetriou M: UDP-N-acetylglucosamine: Alpha-6-D-mannoside beta1, $6 \mathrm{~N}$-acetylglucosaminyltransferase V (Mgat5) deficient mice. Biochim Biophys Acta 1573: 414-422, 2002.

9. Sharma UC, Pokharel S, van Brakel TJ, van Berlo JH, Cleutjens JP, Schroen B, André S, Crijns HJ, Gabius HJ, Maessen J and Pinto YM: Galectin-3 marks activated macrophages in failure-prone hypertrophied hearts and contributes to cardiac dysfunction. Circulation 110: 3121-3128, 2004.

10. Thijssen VL, Hulsmans S and Griffioen AW: The galectin profile of the endothelium: Altered expression and localization in activated and tumor endothelial cells. Am J Pathol 172: 545-553, 2008.

11. Wan SY, Zhang TF and Ding Y: Galectin-3 enhances proliferation and angiogenesis of endothelial cells differentiated from bone marrow mesenchymal stem cells. Transplant Proc 43: 3933-3938, 2011.

12. Dumic J, Dabelic S and Flögel M: Galectin-3: An open-ended story. Biochim Biophys Acta 1760: 616-635, 2006.

13. Papaspyridonos M, McNeill E, de Bono JP, Smith A, Burnand KG, Channon KM and Greaves DR: Galectin-3 is an amplifier of inflammation in atherosclerotic plaque progression through macrophage activation and monocyte chemoattraction. Arterioscler Thromb Vasc Biol 28: 433-440, 2008

14. Lu X, Murphy TC, Nanes MS and Hart CM: PPAR \{gamma\} regulates hypoxia-induced Nox4 expression in human pulmonary artery smooth muscle cells through NF-\{kappa\}B. Am J Physiol Lung Cell Mol Physiol 299: L559-L566, 2010.

15. Henderson NC, Mackinnon AC, Farnworth SL, Kipari T, Haslett C, Iredale JP, Liu FT, Hughes J and Sethi T: Galectin-3 expression and secretion links macrophages to the promotion of renal fibrosis. Am J Pathol 172: 288-298, 2008.

16. Yu L, Quinn DA, Garg HG and Hales CA: Gene expression of cyclin-dependent kinase inhibitors and effect of heparin on their expression in mice with hypoxia-induced pulmonary hypertension. Biochem Biophys Res Commun 345: 1565-1572, 2006.

17. Livak KJ and Schmittgen TD: Analysis of relative gene expression data using real-time quantitative PCR and the 2(-Delta Delta C(T)) Method. Methods 25: 402-408, 2001. 
18. Dong Y, Sui L, Sugimoto K, Tai Y and Tokuda M: Cyclin D1-CDK4 complex, a possible critical factor for cell proliferation and prognosis in laryngeal squamous cell carcinomas. Int $\mathrm{J}$ Cancer 95: 209-215, 2001.

19. Campen MJ, Paffett ML, Colombo ES, Lucas SN, Anderson T, Nysus M, Norenberg JP, Gershman B, Hesterman J, Hoppin J and Willis M: Muscle RING finger-1 promotes a maladaptive phenotype in chronic hypoxia-induced right ventricular remodeling. PLoS One 9: e97084, 2014.

20. Lee JW, Kim HS, Kim S, Hwang J, Kim YH, Lim GY, Sohn WJ, Yoon SR, Kim JY, Park TS, et al: DACH1 regulates cell cycle progression of myeloid cells through the control of cyclin D, Cdk 4/6 and p21Cip1. Biochem Biophys Res Commun 420: 91-95, 2012.

21. Hutcheson R, Terry R, Chaplin J, Smith E, Musiyenko A, Russell JC, Lincoln T and Rocic P: MicroRNA-145 restores contractile vascular smooth muscle phenotype and coronary collateral growth in the metabolic syndrome. Arterioscler Thromb Vasc Biol 33: 727-736, 2013.

22. Rensen SS, Doevendans PA and van Eys GJ: Regulation and characteristics of vascular smooth muscle cell phenotypic diversity. Neth Heart J 15: 100-108, 2007.

23. Hashmi S and Al-Salam S: Galectin-3 is expressed in the myocardium very early post-myocardial infarction. Cardiovasc Pathol 24: 213-223, 2015

24. Ikemori RY, Machado CM, Furuzawa KM, Nonogaki S, Osinaga E, Umezawa K, de Carvalho MA, Verinaud L and Chammas R: Galectin-3 up-regulation in hypoxic and nutrient deprived microenvironments promotes cell survival. PLoS One 9: e111592, 2014.

25. Mor A,Planer D, Luboshits G, Afek A, Metzger S, Chajec-ShaulT, Keren $\mathrm{G}$ and George J: Role of naturally occurring CD4+ CD25+ regulatory $\mathrm{T}$ cells in experimental atherosclerosis. Arterioscler Thromb Vasc Biol 27: 893-900, 2007.

26. Hassoun PM, Mouthon L, Barberà JA, Eddahibi S, Flores SC, Grimminger F, Jones PL, Maitland ML, Michelakis ED, Morrell NW, et al: Inflammation, growth factors, and pulmonary vascular remodeling. J Am Coll Cardiol 54 (Suppl 1): S10-S19, 2009.
27. Chaouat A, Savale L, Chouaid C, Tu L, Sztrymf B, Canuet M, Maitre B, Housset B, Brandt C, Le Corvoisier P, et al: Role for interleukin-6 in COPD-related pulmonary hypertension. Chest 136: 678-687, 2009.

28. Wang Q, Zuo XR, Wang YY, Xie WP, Wang H and Zhang M: Monocrotaline-induced pulmonary arterial hypertension is attenuated by TNF- $\alpha$ antagonists via the suppression of TNF- $\alpha$ expression and NF- $\kappa \mathrm{B}$ pathway in rats. Vascul Pharmacol 58: 71-77, 2013

29. Fouty BW, Grimison B, Fagan KA, Le Cras TD, Harral JW, Hoedt-Miller M, Sclafani RA and Rodman DM: p27(Kip1) is important in modulating pulmonary artery smooth muscle cell proliferation. Am J Respir Cell Mol Biol 25: 652-658, 2001.

30. Zhao Y, Lv M, Lin H, Cui Y, Wei X, Qin Y, Kohama K and Gao Y: Rho-associated protein kinase isoforms stimulate proliferation of vascular smooth muscle cells through ERK and induction of cyclin D1 and PCNA. Biochem Biophys Res Commun 432: 488-493, 2013

31. Arteaga CL: Cdk inhibitor p27Kip1 and hormone dependence in breast cancer. Clin Cancer Res 10 (Suppl): 368S-371S, 2004.

32. Akyurek LM, Boehm M, Olive M, Zhou AX, San H and Nabel EG: Deficiency of cyclin-dependent kinase inhibitors p21Cip1 and p27Kip1 accelerates atherogenesis in apolipoprotein E-deficient mice. Biochem Biophys Res Commun 396: 359-363, 2010.

33. Tanner FC, Boehm M, Akyurek LM, San H, Yang ZY, Tashiro J, Nabel GJ and Nabel EG: Differential effects of the cyclin-dependent kinase inhibitors p27(Kip1), p21(Cip1) and $\mathrm{p} 16$ (Ink4) on vascular smooth muscle cell proliferation. Circulation 101: 2022-2025, 2000

34. Wali MA and Eid RA: Smooth muscle changes in varicose veins: An ultrastructural study. J Smooth Muscle Res 37: 123-135, 2001.

35. Naoum JJ, Hunter GC, Woodside KJ and Chen C: Current advances in the pathogenesis of varicose veins. J Surg Res 141: 311-316, 2007. 